\title{
Controversies in the identification and management of acute pulmonary hypertension in preterm neonates
}

\author{
Regan E Giesinger ${ }^{1}$, Kiran More ${ }^{2}$, Jodie Odame ${ }^{3}$, Amish Jain ${ }^{1}$, Robert P Jankov ${ }^{1}$ and Patrick J McNamara ${ }^{1}$
}

It is increasingly recognized that the abnormal physiologic consequences of pulmonary hypertension (PH) may contribute to poor cardiopulmonary health in premature babies. Conflicting literature has led to clinical uncertainty, pathological misinterpretation, and variability in treatment approaches among practitioners. There are several disorders with overlapping and interrelated presentations, and other disorders with a similar clinical phenotype but diverse pathophysiological contributors. In this review, we provide a diagnostic approach for acute hypoxemic respiratory failure in the preterm neonate, outline the pathophysiological conditions that may present as acute $\mathrm{PH}$, and discuss the implications of high pulmonary vascular resistance (PVR) on the cardiovascular system. Although PVR and respiratory management are highly interrelated, there may be a population of preterm neonates in whom inhaled nitric oxide may improve illness severity and may relate to outcomes. A management approach based on physiology that considers common clinical conundrums is provided. A more comprehensive understanding of the physiology may help in informed decision-making in clinical situations where conclusive scientific evidence is lacking. Regardless, high-quality research is required, and appropriate definition of the target population is paramount. A thoughtful approach to cardiovascular therapy may also provide an avenue to improve neurodevelopmental outcomes while awaiting more clear answers.

A lthough hypoxemic respiratory failure (HRF) is a common problem in premature infants, the relative contribution of primary lung disease vs. failure of normal postnatal decline in pulmonary vascular resistance (PVR) may be difficult to differentiate clinically. The focus of this review is to assist readers in understanding the contribution of acute pulmonary hypertension $(\mathrm{PH})$ to the health of premature infants and appraising strategies to modulate the course. The approach to diagnosis and management of acute $\mathrm{PH}$ in the preterm infant is an area of considerable controversy. The successful utilization of inhaled nitric oxide (iNO) to decrease the requirement for extracorporeal membrane oxygenation in term neonates (1) combined with increased recognition that preterm neonates are also at risk of $\mathrm{PH}$-related clinical consequences has created clinical uncertainty. Clinical course and response to treatment are thought to be developmentally regulated. In addition, diagnosis is confounded by coexisting and confounding illnesses, and therapeutic decision making is obscured by multiple negative trials of iNO in acutely hypoxemic preterms (2).

Although recognized as a problem, the contributory role of $\mathrm{PH}$ to the preterm is uncertain. Specifically, the natural history of pulmonary vascular resistance and right ventricular function in preterms, thresholds at which $\mathrm{PH}$ is physiologically relevant, desirable target oxygen $\left(\mathrm{O}_{2}\right)$ saturation, and the clinical efficacy and/or merits of iNO challenge clinicians on a daily basis. Timely diagnosis and appraisal of actual cardiovascular physiology may enable a more precise approach to treatment. The consequences may include enhanced immediate patient outcomes and possibly lower risk of neurodevelopmental impairment, however research is still needed.

\section{DEFINING PH IN PREMATURE INFANTS}

The precise pulmonary artery pressure (PAP) used to make the diagnosis of $\mathrm{PH}$ in the preterm infant is not clear, particularly in the transitional period. A mean PAP $>25 \mathrm{~mm} \mathrm{Hg}$ is considered abnormal for infants $>3$ months of life (3). A similar diagnostic threshold for preterm infants has not been studied, and the premise that a single threshold is appropriate for neonates at all gestations may be invalid. Systemic arterial pressure rises with gestational age (4); therefore, it may be reasonable to speculate that normative PAP data may be developmentally regulated. In addition there is evidence that PAP may remain at systemic or near-systemic levels in asymptomatic premature infants $(5,6)$. The presence of a high PVR state alone is not sufficient for the diagnosis of $\mathrm{PH}$; however, if severe, the resultant low pulmonary blood flow (PBF) may cause hypoxemia, and contributes to other consequences typical of the $\mathrm{PH}$ phenotype (Figure 1). Failure of the normal decline in PVR to a level that is sufficient to result in adequate PBF for

\footnotetext{
${ }^{1}$ Department of Paediatrics, University of Toronto, Toronto, Canada; ${ }^{2}$ Neonatal Department, Christchurch Women's Hospital, Christchurch, New Zealand; ${ }^{3}$ Department of Physiology, University of Toronto, Toronto, Canada. Correspondence: Patrick J. McNamara (patrick.mcnamara@sickkids.ca)

Received 19 December 2016; accepted 5 August 2017; advance online publication 4 October 2017. doi:10.1038/pr.2017.200
} 


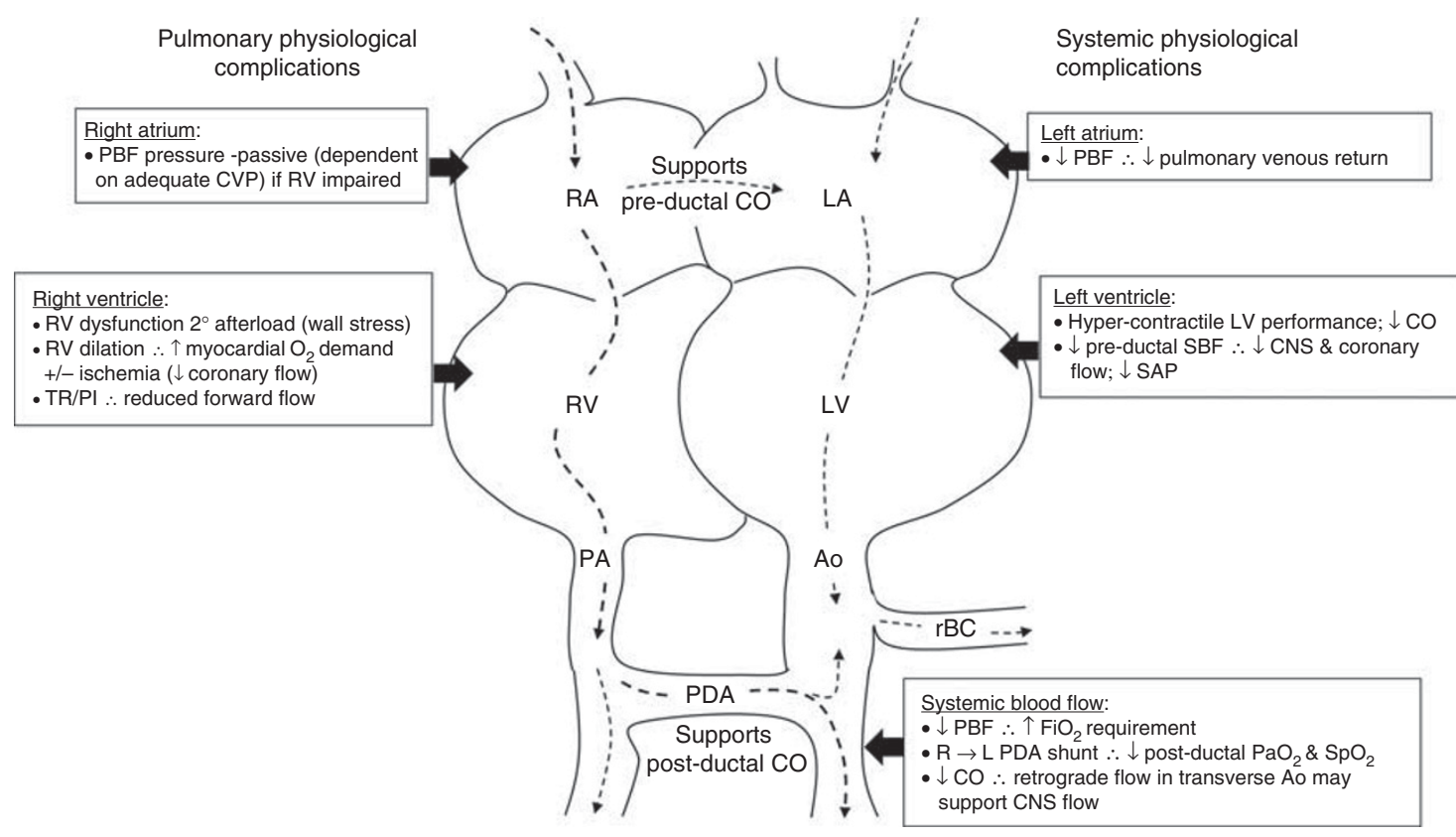

Figure 1. Cardiovascular complications associated with elevated PVR. High PVR results in reduced PBF and reduced CO. High RV afterload contributes to RV dilation and impaired systolic performance. Ao, aorta; CNS, central nervous system; CO, cardiac output; CVP, central venous pressure; $\mathrm{FiO}_{2}$, fraction of inspired oxygen; $\mathrm{LA}$, left atrium; $\mathrm{LV}$, left ventricle; $\mathrm{O}_{2}$, oxygen; $\mathrm{PaO}_{2}$, arterial partial pressure of oxygen; $\mathrm{PBF}$, pulmonary blood flow; PDA, patent ductus arteriosus; RA, right atrium; rBC, right brachiocephalic artery; RV, right ventricle; SAP, systemic arterial pressure; SBF, systemic blood flow; $\mathrm{SpO}_{2}$, oxygen saturation. $\mathrm{PA}$, pulmonary artery.

oxygenation, regardless of the absolute PAP, constitutes a diagnosis of acute $\mathrm{PH}(3)$.

The incidence of $\mathrm{PH}$ in preterms is not clearly described, though a higher frequency than that in term infants has been suggested (7). Parenchymal disease, which is associated with the development of acute $\mathrm{PH}$ in term infants (8), is common in preterms, and it is possible, though not proven, that similar mechanisms are at play. In addition, the immediate postnatal period is characterized by a cascade of cardiopulmonary changes that enable successful transition of the lung from a "vasoconstricted" in utero state to a capacitance organ of gas exchange. The preparation for this process is developmentally regulated (9), suggesting that prematurity may place neonates at increased risk of impaired transition.

The clinical manifestations of acute $\mathrm{PH}$ are phenotypically similar to term neonates. Early refractory hypoxemia, despite effective ventilation strategies and targeted surfactant administration, may relate to extreme lung immaturity in ELBW infants; however, PH may be a contributing factor. The classic signs of oxygen lability and pre/post saturation gradient $>10-15 \%$ may be present if pulmonary pressure exceeds the level of systemic pressure and fetal channels (e.g., ductus arteriosus) remain open with right-to-left shunt (10). Pre- and post-ductal saturation monitoring should be done in all hypoxic preterms by placing saturation probes on the right hand and either lower limb. A diagnosis of PH should not, however, be excluded by the absence of a saturation gradient; specifically, saturations may be equal if ductal shunt is bidirectional, or if the ductus arteriosus is already closed. Coexistent hypoxemia and clinical signs of low cardiac output (e.g., low systolic arterial pressure (SAP) and poor perfusion), should prompt consideration of $\mathrm{PH}$ and/or right ventricular (RV) dysfunction. The accuracy of blood pressure measurement in premature infants with acute $\mathrm{PH}$ during the immediate perinatal period is questionable, as most arterial lines are placed in the post-ductal aorta through the umbilical artery. Theoretically, in the presence of a high-volume rightto-left ductal shunt, this measurement may be a poor surrogate of pre-ductal brain perfusion pressure (Figure 2). In the setting of acute refractory hypoxemia, a high index of suspicion for acute $\mathrm{PH}$ is required to prompt either an echocardiography, if feasible, or a trial of pulmonary vasodilator therapy

A diagnosis of acute $\mathrm{PH}$ is typically made when the aforementioned clinical findings are associated with echocardiographical evidence of elevated PAP in relation to systemic arterial pressure. Pulmonary pressure may be estimated based on several parameters (Table 1) Extra-pulmonary right-to-left shunt across a patent ductus arteriosus (PDA) is indicative of $\mathrm{PH}$, and it has been suggested that bidirectional shunt with $>60 \%$ of systole spent with right-to-left flow is associated with suprasystemic level PAP in term newborns with PPHN, though further study is needed to validate this data (11). The presence of right-to-left shunt is not mandatory for a diagnosis of acute PH. In the absence of a PDA and/or PFO, the velocity of the regurgitant tricuspid jet and/or leftward 


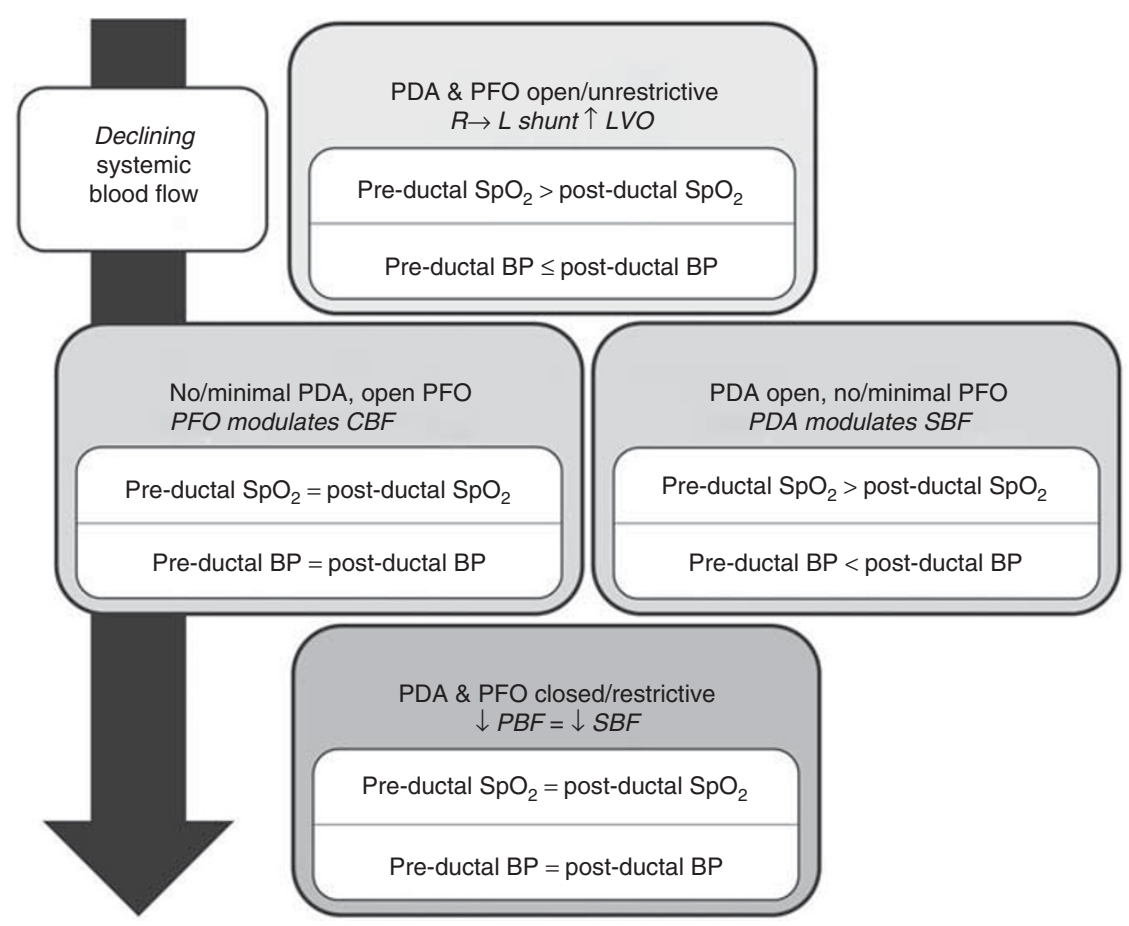

Figure 2. Speculative relationship between oxygen saturation and blood pressure in pre- and post-ductal circulation for preterm neonates with acute $\mathrm{PH}$. The relative magnitude of the shunt is the determinant of the relationship. Unrestrictive right-to-left shunt across the PFO augments preductal cardiac output; unrestrictive right-to-left shunt across the PDA augments post-ductal cardiac output. BP, blood pressure; LVO, left

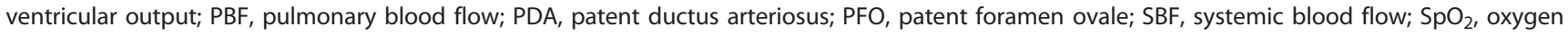
saturation.

deviation of septal motion may be used (Figure 3). Ancillary evidence of RV dilation or dysfunction and low pulmonary venous return as evidenced by low pulmonary vein, transmitral flow, and low-left ventricular output may be used to support the diagnosis, though it is important to consider that $\mathrm{RV}$ dysfunction may occur in the absence of elevated PAP and, therefore, in the absence of specific evidence of $\mathrm{PH}$, these should be interpreted with caution. Targeted Neonatal Echocardiography (TnECHO), in particular, may provide invaluable insights in real-time at the bedside, although research is limited. TnECHO allows the rapid assessment of indirect measures of PVR (e.g., ratio of RV ejection time to pulmonary artery acceleration time), PAP, myocardial dysfunction, and its cardiovascular consequences (Table 1). There is limited, but increasing, reference data for measures of RV performance in the preterm infants, particularly in the transitional period $(12,13)$. This may enable enhanced diagnosis and recognition of cardiovascular implications, which may provide an avenue to improve therapeutic precision.

\section{CONTRIBUTORS TO ACUTE HYPOXEMIA: DIFFERENTIAL DIAGNOSIS}

The ELBW neonate with severe hypoxemia, despite positive pressure ventilation and provision of $100 \% \mathrm{O}_{2}$, represents a diagnostic challenge. Oxygenation depends on the adequacy of lung recruitment and respiratory function, vascular recruitment, blood flow, and cardiac status (Figure 4). Lung disease is common and may have several contributors.
Particularly in the acutely hypoxic ventilated preterm infant, it is important that mechanical factors be evaluated (e.g., equipment function, endotracheal tube patency, and position) and air leak is ruled out. Parenchymal lung disease is typically associated with increased work of breathing, abnormally aerated lungs on $\mathrm{X}$-ray, and poor lung compliance. Assessment of arterial $\mathrm{CO}_{2}$ is recommended as capillary and venous samples may be less reliable in the setting of poor perfusion. Importantly, lung inflation may impair gas exchange and oxygenation either through over- or underrecruitment that may independently contribute to an increase in PVR, further complicating the diagnosis and management of acute $\mathrm{PH}$.

Though unusual, it is critical to maintain an index of suspicion for CHD as a differential diagnosis in these patients. Neonates with CHD may be born preterm without antenatal detection, and subgroups of neonates with anatomically normal hearts may also be at risk of impaired myocardial performance. In particular, infants with single ventricle physiology and/or duct-dependent systemic blood flow lesions, e.g., hypoplastic left heart syndrome and aortic stenosis may be negatively impacted by non-judicious use of pulmonary vasodilator therapy. Hypoxemia may also occur due to impaired PBF or due to reduced systemic delivery of oxygenated blood in neonates with RV and LV dysfunction, respectively. In particular, birth asphyxia (14) and twin-totwin transfusion syndrome (15) have been associated with increased risk of myocardial dysfunction in preterms, 


\section{Review | Giesinger et al.}

Table 1. Assessment of the right ventricle (RV)

\begin{tabular}{|c|c|c|c|}
\hline Assessment & Measurement & Advantages & Limitations \\
\hline \multicolumn{4}{|c|}{ Established in clinical practice } \\
\hline \multirow[t]{3}{*}{ RV systolic pressure } & Peak velocity of TR jet & $\begin{array}{l}\text { Calculation of RVSp (modified Bernoulli } \\
\text { equation) }\end{array}$ & $\begin{array}{l}\text { Incomplete or inadequate TR (131) } \\
\text { Underestimated by RV dysfunction (131) } \\
\text { Assumes RA pressure }\end{array}$ \\
\hline & $\begin{array}{l}\text { Septal wall motion (eccentricity } \\
\text { index (132)) }\end{array}$ & $\begin{array}{l}\text { Direct assessment of relative LVSp and } \\
\text { RVSp over the duration of the cardiac } \\
\text { cycle }\end{array}$ & $\begin{array}{l}\text { Relative to systemic pressure; systemic } \\
\text { hypertension may underestimate RVSp }\end{array}$ \\
\hline & PDA shunt direction & $\begin{array}{l}\text { Direct assessment of relative systemic } \\
\text { and pulmonary pressure over the } \\
\text { duration of the cardiac cycle }\end{array}$ & Absence of PDA \\
\hline $\begin{array}{l}\text { RV systolic } \\
\text { performance }\end{array}$ & RV output & $\begin{array}{l}\text { Reflects volume of PBF in the absence of } \\
\text { pulmonary to aortic shunt }\end{array}$ & $\begin{array}{l}\text { Angle dependent } \\
\text { Precise annulus measurement may be } \\
\text { technically difficult due to suboptimal } \\
\text { visualization of PA }\end{array}$ \\
\hline \multirow[t]{2}{*}{$\begin{array}{l}\text { Systemic blood } \\
\text { flow }\end{array}$} & LV output & $\begin{array}{l}\text { Reflects volume of SBF } \\
\text { If PDA open, only preductal (CNS, } \\
\text { coronary) SBF }\end{array}$ & $\begin{array}{l}\text { Angle dependent; requires precise placement of } \\
\text { sample volume } \\
\text { Precise annulus measurement dependent on } \\
\text { alignment of PLx plane }\end{array}$ \\
\hline & $\begin{array}{l}\text { Qualitative assessment of LV } \\
\text { filling; mid-cavity flow } \\
\text { acceleration }\end{array}$ & Easily visualized, rapid. & $\begin{array}{l}\text { Imprecise } \\
\text { Detects abnormalities only at the extremes of } \\
\text { filling }\end{array}$ \\
\hline
\end{tabular}

Evidence of utility in other populations (limited normative data, longitudinal assessment may be advantageous)

Pulmonary vascular RVET:PAAT ratio resistance

Mid-systolic notching of PA Doppler waveform

RV systolic performance
RV fractional area change

TAPSE (Tricuspid annular plane systolic excursion)

Tissue Doppler imaging
Predictive of $\mathrm{PH}$ (133)

Easily measured, not angle dependent

Associated with PH (133)

Easily measured, not angle dependent

Reflective of RV ejection fraction on MRI (134) (adult data)

Highly reproducible measure (longitudinal motion) (135) Feasible in most patients $(134,136)$

Highly reproducible measure of longitudinal RV performance (136) Feasible in most patients
Influenced by poor RV performance

Confounded by concurrent TR, PA dilation, PDA shunt

Influenced by poor RV performance

Confounded by TR, PA dilation, PDA shunt

May occur in high flow states (133)

Dependent on high-quality imaging windows for endocardial definition (135)

Apical 4 chamber FAC influenced by septal motion (134)

Reflects displacement of tricuspid annulus at a single point; \#septal or outlet motion; \#RWM abnormalities $(134,136)$

Angle and possibly load dependent (134)

Reflects displacement of tricuspid annulus at a single point; \#septal or outlet motion; \#RWM abnormalities

Affected by overall motion of the heart, angle and load (134)

Research/investigational use

\section{RV peak systolic strain \\ Allows segmental assessment of RWM \\ Influenced by image quality \\ Limited normative data}

CNS, central nervous system; FAC, fractional area change; LV, left ventricle; LVSp, left ventricular systolic pressure: MRI, magnetic resonance imaging; PA, pulmonary artery: PAAT, pulmonary artery acceleration time; PBF, pulmonary blood flow; PDA, patent ductus arteriosus; PH, pulmonary hypertension; PLx, parasternal long axis; RV, right ventricle; RVET, right ventricular ejection time; RVSp, right ventricular systolic pressure; RWMA, regional wall motion; TR, tricuspid regurgitation.

independent of increased RV afterload secondary to acute $\mathrm{PH}$. Immaturity may make ELBW infants especially vulnerable to LV systolic dysfunction $(16,17)$ and may, in vulnerable preterms, become clinically relevant.

Differentiating pre-capillary acute $\mathrm{PH}$ from post-capillary disease due to pulmonary venous hypertension (PVH) requires echocardiography, and is clinically relevant as the management approach will differ. First, ELBW infants are at increased risk of left heart disease with diastolic dysfunction due to myocardial immaturity (18). Specifically, the preponderance of non-contractile tissue (19), relatively fewer myofibrils that are disorganized (20), and immature calcium handling systems (21) may contribute to LV diastolic dysfunction at baseline (22). Second, increased LV afterload, 


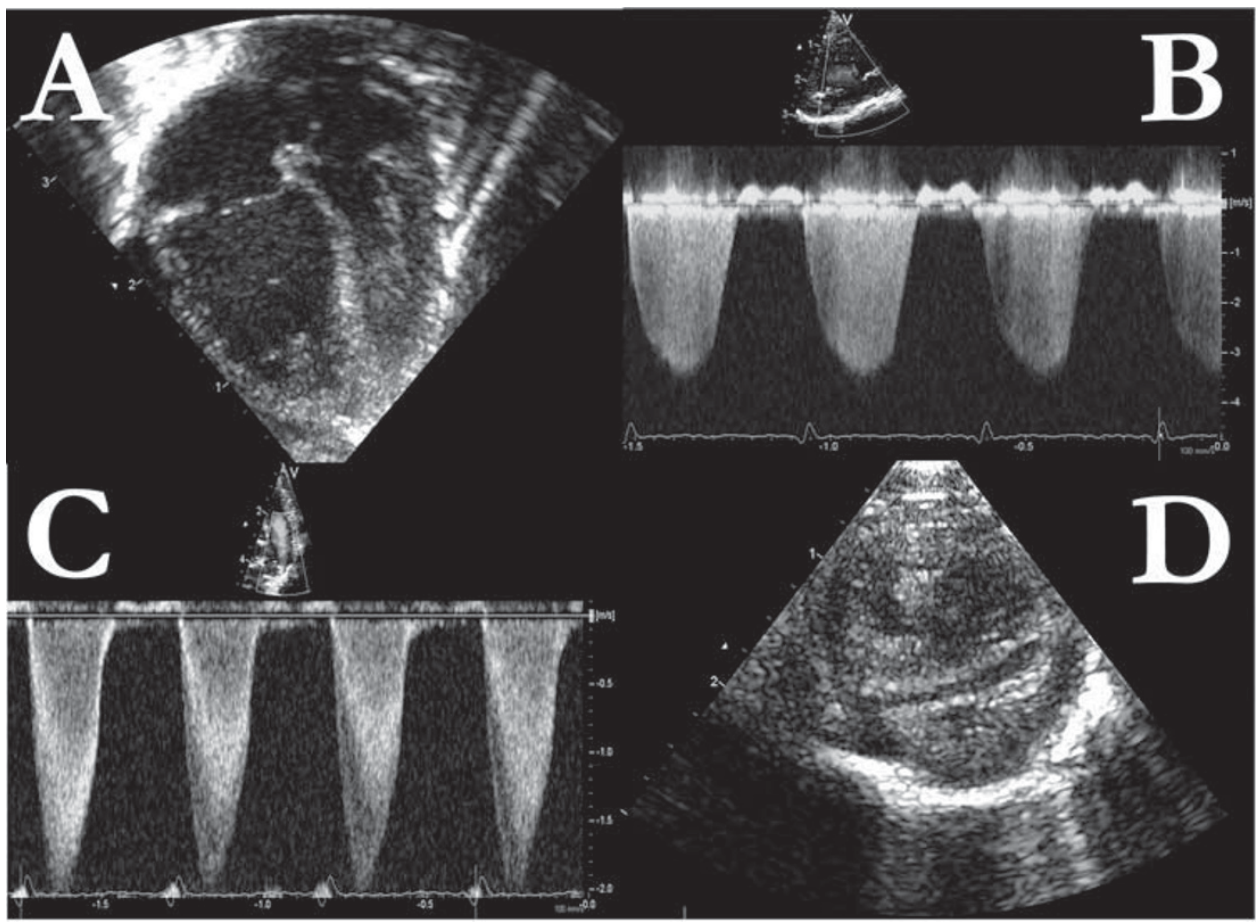

Figure 3. Echocardiography features associated with pulmonary hypertension. (a) Apical 4-chamber view demonstrating a dilated right atrium and right ventricle with leftward deviation of the intraventricular septum and associated under filled left ventricle. (b) Continuous wave Doppler of the tricuspid regurgitant jet measured in the parasternal long-axis plane with a peak velocity of $3.46 \mathrm{~m} / \mathrm{s}$ corresponding to an estimated right ventricular systolic pressure of $48 \mathrm{~mm} \mathrm{Hg}+$ right atrial pressure. (c) High-velocity right-to-left shunt across a small ductus arteriosus from a parasternal short-axis plane. (d) Parasternal short-axis view at the level of the chordae tendineae of the mitral valve demonstrating a dilated right ventricle on top with paradoxical septal motion at end-systole.

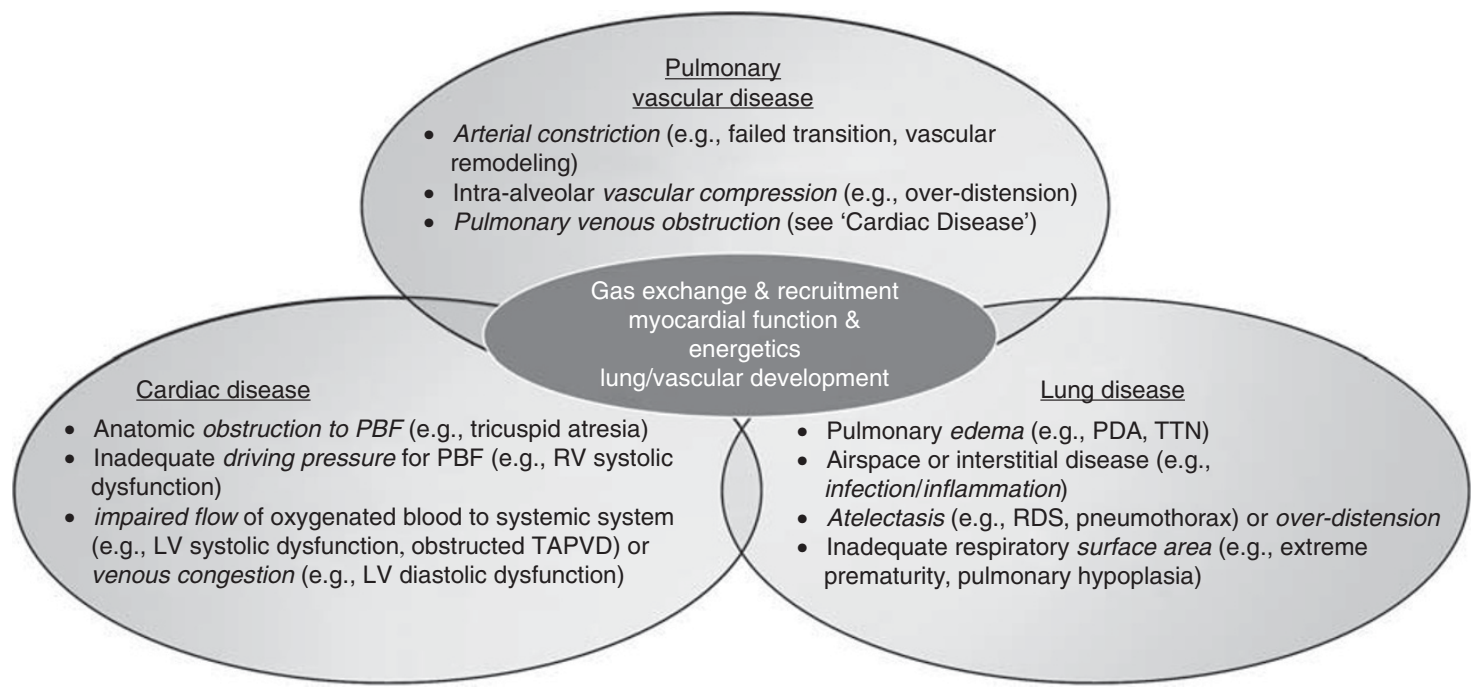

Figure 4. Possible contributors to hypoxic respiratory failure in preterm infants. Complex pathophysiology may exist when multiple overlapping disease processes occur concurrently. There is considerable interdependency intrinsic in cardiorespiratory interactions. LV, left ventricle; PDA, patent ductus arteriosus; RDS, respiratory distress syndrome; RV, right ventricle; TAPVD, total anomalous pulmonary venous drainage; TTN, transient tachypnea of the newborn.

during transition or after the administration of exogenous vasoconstrictors, may also contribute to an increase left atrial, and therefore pulmonary venous pressure. Finally, left heart volume overload may also contribute to reduced left atrial compliance (23). Non-discriminate use of selective pulmonary vasodilators in this setting may be harmful. Specifically, a marked increase in PBF (e.g., escalating left-to-right PDA shunt) may, therefore, contribute to the development of PVH. 
It is unknown whether the mechanisms by which PVH contributes to secondary PAH in older patients (24) are active in preterm infants.

It may be difficult to determine the relative contributions of parenchymal, vascular, and cardiac disease in preterm neonates who have a high risk of multiple overlapping disease processes. The complexity of the cardiorespiratory system and the interrelatedness of both disease physiology and treatment make diagnostic precision important. Echocardiography is recommended for all preterm infants with HRF in the absence of parenchymal lung disease. The presence of parenchymal lung disease may modify the urgency of echocardiography; however, if accessible, imaging should be considered in preterms with ongoing severe hypoxemia despite normalization of $\mathrm{CO}_{2}$ or with clinical features of cardiovascular instability such as low SAP or poor perfusion.

\section{IMPLICATIONS OF HIGH PVR ON MYOCARDIAL FUNCTION}

There is limited data specific to the impact of PVR on preterm myocardial function, though a similar decline in RV performance as in term neonates is reported (25). An understanding of the impact of PVR on the myocardium is important because it may significantly modify disease pathophysiology and in term neonates may be a predictor of poor outcome (26). Fetal myocardial performance remains stable over the latter half of pregnancy $(27,28)$, and animal data suggest that changes in loading conditions produce similar changes in contractility across gestations. The importance of these physiological concepts and the similarity of the disease phenotype across gestation warrants extrapolation of term data to preterms until further scientific data are available.

The fetal RV is the dominant ventricle and supplies approximately two-third of the combined cardiac output (29). There are important differences between the two ventricles related to their differing roles in utero. As compared with the LV, the fetal RV is much larger and has a higher baseline wall stress on the basis of a larger circumference-towall thickness ratio (30). As the fetus matures, the ventricles grow proportionally until birth when, under normal conditions, there is a rapid decline in PVR and the RV undergoes structural changes to adapt to the new lower-pressure pulmonary circuit $(20,31)$. If PVR does not decline normally, the RV may be exposed to excessive afterload, to which it is poorly able to adapt, and myocardial function is negatively impacted $(30,32,33)$. There is also evidence of abnormal LV function in term infants with acute $\mathrm{PH}$ (34). The myocardium is made up of a network of continuous myocardial fibers that traverse both ventricles in a complex pattern (35); therefore, in theory, factors that negatively influence the performance of the RV may have a broader impact. Contributors to abnormal LV systolic performance include altered configuration of the septal wall (36), reduced left heart preload $(37,38)$, and the effects of systemic hypoxemia and hypotension on coronary oxygen delivery. The presence of fetal shunts may have a significant impact on loading conditions (Figure 2). A closing or restrictive ductus arteriosus may add to RV afterload and further compromise systolic performance. The presence of a widely patent foramen ovale may partly mitigate the impact on decreased LV preload through right-to-left shunt.

\section{MANAGEMENT CONTROVERSIES FOR PRETERM INFANTS WITH ACUTE PH}

\section{Oxygen Saturation Targets}

The insurance of adequate arterial oxygen content to maintain tissue physioxia represents the cornerstone of neonatal cardiovascular care. At term, this begins with establishing an airway and optimum lung recruitment with the therapeutic target of optimum alveolar gas content. This strategy alone may be adequate for some neonates. Thereafter, recommended therapeutic strategies are those that reduce PVR and support RV function. Although, in general, these principles appear straightforward, the implementation may be complicated.

The ideal target oxygen saturation $\left(\mathrm{SpO}_{2}\right)$ for preterm neonates is unclear, particularly with acute $\mathrm{PH}$. In term animal experimental models both alveolar hypoxia and hypoxemia independently stimulate pulmonary vasoconstriction (39). At arterial partial pressure of oxygen $\left(\mathrm{PaO}_{2}\right)$ between 20 and $40 \mathrm{~mm} \mathrm{Hg}$ there is an inverse linear relationship with PAP until reaching a plateau at $50 \mathrm{~mm} \mathrm{Hg}$ $\mathrm{PaO}_{2}$, after which no further reduction in PAP occurs (40). Maturity, however, is an important modifier of this relationship. The responsiveness of the pulmonary vasculature to oxygen increases throughout gestation, with the greatest change in the third trimester (41). When exposed to hyperbaric $\mathrm{O}_{2}$, the increase in PBF of extremely preterm fetal lambs is significantly blunted, despite a similar increase in pulmonary artery $\mathrm{O}_{2}$ tension as compared with at term fetal lambs (42). The role of $\mathrm{O}_{2}$, therefore, as a pulmonary vasodilator in preterm neonates is variable and in some situations may be reduced.

In fact, provision of high concentrations of $\mathrm{O}_{2}$ in an effort to reduce PVR, may be detrimental to lung health and counterproductive in the acute management of $\mathrm{PH}$. In preterm lambs, exposure to $24 \mathrm{~h}$ of hyperoxia is associated with lung injury and inflammation (43). Exposure to reactive oxygen species (ROS) with inadequate defenses are implicated as a contributor. The antioxidant enzyme (AOE) system is immature in preterm animals and demonstrates significant maturational change $(44,45)$. Superoxide dismutase activity in the human fetus at $18-20$ weeks GA is $\sim 35 \%$ its term level, suggesting a similar ontogeny (46). Particularly in the immediate postnatal period, low baseline levels may make preterm neonates vulnerable to the effects of ROS, though this may be mitigated in part by antenatal corticosteroids (47).

Immaturity of the AOE response to hyperoxia may also be important. In term and near-term animals, hyperoxia upregulates AOE activity after $24-72 \mathrm{~h}$ of exposure to ROS $(46,48,49)$. There is evidence that this response may be blunted in preterms; specifically, AOE activity is not upregulated despite hyperoxia in the preterm rabbit (48) 
and baboon (50), and a preterm lamb model demonstrates low AOE activity despite the presence of oxidative stress (43). In addition to cellular injury produced by excessive or prolonged exposure, ROS may negatively impact preterms with acute $\mathrm{PH}$ indirectly. ROS are known to combine with nitric oxide $(\mathrm{NO})$ to produce nitrogen dioxide $\left(\mathrm{NO}_{2}\right)$ and peroxynitrite. These compounds may further augment PVR. Though preterm data are not available, peroxynitrite is associated with enhanced pulmonary vasoconstriction in term neonatal, but not in adult rat (51). Simultaneously, the resultant reduction in the bioavailability of endogenously produced NO may actually augment vasoconstriction (43).

In practice it may be difficult to determine the optimum $\mathrm{PaO}_{2}$ to balance the beneficial effects on PVR with the adverse consequences of oxidative stress. Nevertheless, while it is important to maintain tissue oxygenation and healthy cellular metabolic homeostasis, avoidance of hyperoxia is an important consideration. Based on the higher affinity of fetal hemoglobin for $\mathrm{O}_{2}$ (52), a target $\mathrm{SpO}_{2}$ between 90 and $95 \%$ to maintain a $\mathrm{PaO}_{2}$ in the $50-70 \mathrm{~mm} \mathrm{Hg}$ range may be prudent. In the presence of an oxygen saturation gradient, preductal saturation should be used to guide $\mathrm{O}_{2}$ therapy, as this represents the $\mathrm{O}_{2}$ delivery to the brain. An effort to increase the postductal saturation by providing high concentration of $\mathrm{FiO}_{2}$ is not recommended, as there is likely to be limited supplemental pulmonary vasodilation and production of additional ROS. On the contrary, randomized trials of oxygen target saturation for all-comer preterms have shown that lower target saturations (85-90\%) are associated with an increased risk of mortality, further complicating the dilemma $(53,54)$.

\section{Approach to Respiratory Support}

Optimal lung recruitment is an important component of treatment of acute $\mathrm{PH}$. In an isolated perfused lung experimental model, the relationship between PVR and lung volume shows a hysteresis curve similar to the relationship between airway pressure and volume. With lung inflation there is a modest increase in PVR with a steeper decline in deflation (55). Below closing volume, however, deflation increases PVR. Respiratory distress syndrome is associated with reduced functional residual capacity, which may lower the closing volume $(56,57)$. In these patients, recruitment alone or in combination with surfactant therapy may increase functional residual capacity and reduce PVR (57). For preterm infants with HRF in the setting of respiratory distress syndrome, surfactant should be administered as a first-line therapy. For infants who remain hypoxic after surfactant in whom $\mathrm{PH}$ is either suspected or proven, caution is advised when considering additional surfactant doses as its delivery may cause transient airway obstruction and impair alveolar ventilation (58). Reactive vasoconstriction, in theory, may precipitate acute pulmonary hypertensive crisis, which may contribute to prolonged hypoxia (58).

The "open-lung" ventilation strategy, characterized by using positive end-expiratory pressure and relatively small tidal volumes following a recruitment maneuver to open collapsed lung units and optimize functional residual capacity, is widely utilized with a goal of minimizing ventilator-induced lung injury. No specific mode of ventilation has consistently demonstrated superiority; however, irrespective of the mode, avoidance of under-recruitment or hyperinflation is important. When lung volume is excessive, airway pressure exerts a compressive force against the capillaries within respiratory units and is associated with increasing PVR (59), reduced PBF (60), reduced LV end-diastolic volume, (61) LV stroke volume (61), and reduced systemic perfusion (62).

The clinical challenge, particularly with the use of highfrequency ventilation, is to determine when the optimum lung volume has been achieved. Increasing mean airway pressure and lung volume are strongly associated. Owing to highly variable patient-related factors (e.g., lung compliance), predicting lung volume on the basis of mean airway pressure alone in preterms is not reliable (63). Commonly used radiological markers (e.g., diaphragm position relative to posterior ribs) lack precision (64). Though oxygenation is a useful surrogate marker of recruitment in animal (65) and neonatal studies $(66,67)$, it may be unreliable in neonates with acute $\mathrm{PH}$. In addition, V/Q mismatch may not be corrected by improved alveolar aeration and over-distension may further compromise hemodynamics. Regular assessment of lung compliance is recommended, and a high index of suspicion for over-distension is warranted. TnECHO assessment of RV output, which declines with increasing distending pressure, may provide additional insight, though further study is required to identify if a predictable threshold exists $(68,69)$. Indices of left heart filling and inferior vena cava distensibility may provide additional insights, but there is limited data regarding their validity.

The role of iNO is established in term and near-term neonates with PPHN (1), but remains controversial in preterm infants with acute $\mathrm{PH}$. Several randomized trials of rescue iNO vs. placebo have enrolled patients on the basis of respiratory illness severity alone without confirming the presence or absence of $\mathrm{PH}$ on echocardiography. These trials, however, were not designed to investigate the role of iNO as a pulmonary vasodilator in acute $\mathrm{PH}$. Inclusion criteria, disease severity and primary outcome were variable and echocardiography-proven $\mathrm{PH}$ was reported infrequently, which contributes to clinical uncertainty as to the impact of iNO therapy on illness severity and outcome measures (Table 2). The relatively high cost of iNO delivery systems creates an additional layer of complexity in many healthcare environments as there may be financial disincentives to its use without a clear expectation of its benefit. There are anecdotal reports of American insurance payers declining to cover the cost of iNO delivery to preterm infants, citing the lack of evidence of benefit. In some centers, stewardship programs have been instituted and, though "appropriate use" is the goal, an emphasis on avoidance of cost may lead to pressure on clinicians to strive for "minimum use". A thoughtful appraisal of the literature is warranted to guide clinical decision-making 
Review | Giesinger et al.

Table 2. Characteristics of randomized controlled trials of nitric oxide for early rescue therapy of hypoxic respiratory failure in preterm infants.

\begin{tabular}{|c|c|c|c|c|c|}
\hline Identifier & $\mathrm{GA} / \mathrm{wt}, n$ & Inclusion criteria & Intervention/duration & Primary outcome & $\begin{array}{c}\mathrm{PH} \text { on echo } \\
(n, \%)\end{array}$ \\
\hline Mercier et al. (77) & $<33 / 40, n=85$ & $\begin{array}{l}\text { Ol } 12.5-30 \\
\leq 7 \text { days of life }\end{array}$ & $\begin{array}{l}\text { 10-20 p.p.m. (based on OI) } \\
\text { Duration unclear }\end{array}$ & Reduction in Ol after $2 \mathrm{~h}$ & Not reported \\
\hline $\begin{array}{l}\text { Srisuparp et al. } \\
(137)\end{array}$ & $<2 \mathrm{~kg}, n=34$ & $\begin{array}{l}\text { Clinical RDS, surfactant } \\
\text { Ol varied by BW }(\min 4 \text {, } \\
\max 12) \\
\leq 72 \mathrm{~h} \text { of life }\end{array}$ & $\begin{array}{l}20 \text { p.p.m. } \\
\text { Max of } 7 \text { days }\end{array}$ & $\begin{array}{l}\text { Effects of iNO on } \\
\text { oxygenation }\end{array}$ & Not reported \\
\hline Su et al. (74) & $\begin{array}{l}\leq 31 / 40 \& \leq 1.5 \mathrm{~kg} \\
n=65\end{array}$ & $\mathrm{Ol} \geq 25$ & $\begin{array}{l}\text { 5-20 p.p.m. } \\
\downarrow \text { by } 1 \text { p.p.m. Q6h as dictated } \\
\text { by } \mathrm{FiO}_{2}\end{array}$ & $\begin{array}{l}\text { Effects of iNO on } \\
\text { oxygenation }\end{array}$ & Not reported \\
\hline Wei et al. (75) & $\leq 34 / 40, n=60$ & $\begin{array}{l}\text { MV, } 2 \text { h after surfactant } \\
\text { OI } \geq 11 \\
<7 \text { days of life }\end{array}$ & $\begin{array}{l}5 \text { p.p.m. starting } \\
\text { At least } 7 \text { days or when } \\
\text { extubated }\end{array}$ & $\begin{array}{l}\text { Ol before and during } \\
\text { treatment }\end{array}$ & Not reported \\
\hline
\end{tabular}

and direct policy-makers. The extrapolation of the results of these trials to conclude that there is no role for iNO in the management of preterm neonates with acute $\mathrm{PH}$ in the presence of high PVR represents a physiological oversimplification.

Evidence from moderately preterm animal models supports a reduction in pulmonary vascular tone (70) with augmentation of $\mathrm{PBF}$ and improved oxygenation in response to exogenous NO (71). Several human clinical trials of iNO have reported improved oxygenation in hypoxic preterms as compared with controls (72-75), though this effect is not consistent across all populations reported, which may relate to phenotypic variability in the patients selected. The modulators of iNO responsiveness in preterm infants have not been firmly established, though larger birth weight (76) and older gestational age $(7,77)$ have been suggested as predictors of positive response. The published data exploring the relationship between $\mathrm{PH}$ and iNO response are limited to observational data $(7,78)$. In selected populations presenting with HRF and a high pre-test probability of abnormal PVR, such as those with prolonged oligohydramnios, iNO is effective regardless of gestational age (79-81). A recent retrospective cohort study suggests that the response rate to iNO in preterm infants with echocardiography-proven $\mathrm{PH}$ in the first $72 \mathrm{~h}$ of life is comparable to term data and independent of gestational age (82).

The use of iNO in an unselected population without the use of echocardiography, however, may be dangerous. Before considering iNO therapy, it is important to consider the cardiovascular implications of a potentially marked change in PBF. For example, confirmation of normal LV systolic performance is essential as theoretically, in patients with significant LV systolic dysfunction, the right-to-left ductal shunt is a major determinant of the adequacy of systemic blood flow (SBF). Indiscriminate use of iNO may precipitate cardiogenic shock by reversing the transductal shunt, and increasing PBF at the expense of SBF. These patients may be identified by comprehensive echocardiography evaluation of
LV performance and shunt physiology; specifically, the coexistence of right-to-left PDA shunt and left-to-right transatrial shunt in patients with moderate to severe LV dysfunction may represent an alternative physiology. The clinical assessment of this patient population may be challenging due to the presence of a pre-/post-ductal oxygen saturation difference. Careful evaluation of the effect of oxygen may provide some physiologic insight as these patients are likely to have relatively normal pre-ductal oxygen saturation in room air. We recommend judicious use of iNO in these patients, early post-intervention echocardiography, and immediate discontinuation of iNO in patients with either a lack of improvement in oxygenation or deterioration in clinical indices of systemic perfusion. Preterm neonates with a PDA need to be monitored carefully after iNO administration, as they are at increased risk of pulmonary hemorrhage (83) as a manifestation of a rapid reduction of PVR due to escalating left-to-right shunt; similarly, the marked change from a hypoxemic, low-cardiac output state to a state of normoxia or hyperoxia with high-cardiac output due to PDA shunt, may predispose neonates to cerebral ischemiareperfusion injury and intraventricular hemorrhage (IVH) (84). Further studies are needed to delineate these risks and close monitoring is advised. Early echocardiography after iNO initiation may be particularly useful to monitor the evolution of the disease and response to treatment, particularly in patients with LV dysfunction. Rapid improvement in oxygenation (e.g., $30 \mathrm{~min}$ ) has been reported in both preterm animal $(71)$ and human studies $(74,85)$.

The appropriate starting dose and duration of iNO after a clinical response may, theoretically, require modification based on the unique characteristics of preterm circulation. Animal studies suggest a dose-response relationship between 5 and 20 p.p.m. of iNO (71), however, there are no human preterm pharmacokinetics studies, and there is insufficient data to determine superiority of one regime (e.g., starting at 5 p.p.m. and increasing) over another (e.g., starting at 20 p.p. $\mathrm{m}$. and then weaning). Similarly, there is no standard 
approach to weaning, and on both subjects the published literature varies widely (Table 2). Modification of guidelines to reflect these unique physiological vulnerabilities (e.g., IVH, pulmonary hemorrhage) may be necessary, though there is no concrete scientific evidence to support this in practice. As PAP and PVR decline, progressive pulmonary edema and $\mathrm{O}_{2}$ stress may further contribute to adverse pulmonary outcomes. The relationship of iNO to free radical production in human neonates is unclear. There is biological evidence that ROS are constitutively produced by cellular sources; however, when combined with $\mathrm{O}_{2}$, NO creates supra-physiologic levels of nitrogen dioxide $\left(\mathrm{NO}_{2}\right)$ and peroxynitrite (86). In acutely unwell neonates, reduction in ROS may offset $\mathrm{NO}_{2}$ effects. Excessive or prolonged exposure may cause cellular injury and compromise cell growth (86). Given the body of evidence advocating against the use of iNO routinely in the prevention of preterm morbidities, especially bronchopulmonary dysplasia (2), avoidance of exposure to iNO beyond the period required to reverse abnormal PVR and its consequences is recommended. Once oxygenation has improved, the continued role of iNO is questionable and early weaning and discontinuation should be considered.

The impact of acute rescue therapy with iNO on survival and preterm morbidity is, however, conflicting. Some studies have suggested that iNO treatment may be associated with complications such as IVH (87) and higher oxygen dependency (88), whereas others report reduced incidence of IVH and mortality (75). Preterm infants with prolonged oligohydramnios who receive iNO treatment, however, have improved oxygenation and lower mortality (89). The fact that randomized controlled trials have shown no consistent benefit in terms of mortality, bronchopulmonary dysplasia, or IVH (2) is not unexpected given the complexity of the disease physiology and variability in treatment approach. The subclinical existence of alternative disease states (e.g., LV dysfunction), which may represent a contraindication to treatment and failure to stratify for response, may also confound the results. Recent observational data demonstrated that iNO responders (vs. non-responders) may have improved disability-free survival, suggesting that responsiveness may have prognostic implications (). Survivors may also have a reduced risk of bronchopulmonary dysplasia and severe brain injury (80), though it is difficult to draw definitive conclusions based on retrospective data and small sample sizes. A significant limitation of many studies attempting to address this question is lack of accurate physiological clarity. In the absence of echocardiography documentation of disease physiology and rigorous diagnostic criteria for acute $\mathrm{PH}$, it is difficult to draw conclusions as to the potential impact on outcome. There is no randomized controlled trial of acute rescue iNO therapy for preterm infants with echocardiography-confirmed PH. Given the low disease frequency within individual centers, such a trial would be extremely difficult to undertake and would necessitate a large multi-center design. In addition, therapeutic efficacy is likely dependent on a variety of cardiovascular and respiratory confounders, the approach to which would be difficult to standardize across multiple individual practitioners.

Despite the limitations of the current body of literature, a trial of iNO is strongly recommended for preterm infants with echocardiography-confirmed $\mathrm{PH}$ and severe hypoxemia, despite optimum management of lung disease (3). A history of prolonged oligohydramnios may strengthen the likelihood of benefit, however, whether this effect represents enhanced responsiveness or improved diagnostic precision is unclear. Its use should be avoided in patients with significant LV dysfunction and the use of the lowest required dose and duration are prudent to minimize the risks of IVH, pulmonary hemorrhage, oxidative stress, and ductal physiology. Close physiological monitoring including serial echocardiography is highly recommended.

The role of alternative pulmonary vasodilators in this population is unclear with limited published evidence. Sildenafil is a non-selective phosphodiesterase 5 (PDE-5) inhibitor used to treat acute $\mathrm{PH}$ and/or RV dysfunction with evidence of benefit in term infants with PPHN. There are reports of reduced OI after administration of both intravenous and oral sildenafil to a heterogeneous group of preterms with $\operatorname{HRF}(91,92)$; however, both safety and efficacy data are extremely limited. An association between sildenafil and retinopathy of prematurity has been proposed on the basis of a biologically plausible connection between PDE-5 inhibition and NO-mediated vasoproliferation in the retina (93-95). It is difficult, however, to separate the impact of sildenafil from concurrent neonatal risk factors for retinopathy of prematurity (e.g., significant $\mathrm{O}_{2}$ exposure, PDA ligation) in reported cases. A few small human studies suggest no increased risk $(96,97)$ and $\mathrm{O}_{2}$-mediated neovascularization is reduced by sildenafil administration in a mouse model (98). In sick preterms with concurrent cardiovascular instability, the nonspecific vasodilator effects on systemic blood pressure also merit consideration. Oral sildenafil use for $\mathrm{PH}$ has been associated with severe hypotension in extreme preterm neonates (99). Drug levels achieved intravenously change markedly in term neonates over the first week of life (100). Preterm pharmacokinetics have not been studied, however, there is likely significant heterogeneity due to changes in the cytochrome P450 enzyme system with ontogeny (101), and there is high risk for drug-drug interactions with similarly metabolized agents (e.g., fluconazole, caffeine, phenobarbital) (102). The use of sildenafil as an alternative to iNO is not currently recommended, and its use as an adjunctive agent has not been adequately studied in preterm infants.

Milrinone (phosphodiesterase-3, PDE-3 inhibitor) mediates vascular smooth muscle vasodilation through an increase in cyclic AMP (103). In mature patients, milrinone provides positive inotropy and reduces both systemic vascular resistance and PVR (104). In adult animals there is benefit to combination therapy with $\mathrm{iNO}$, which may be related to synergy between upregulation of the cAMP and cGMP pathways (105). Preterm data are sparse and inotropic 


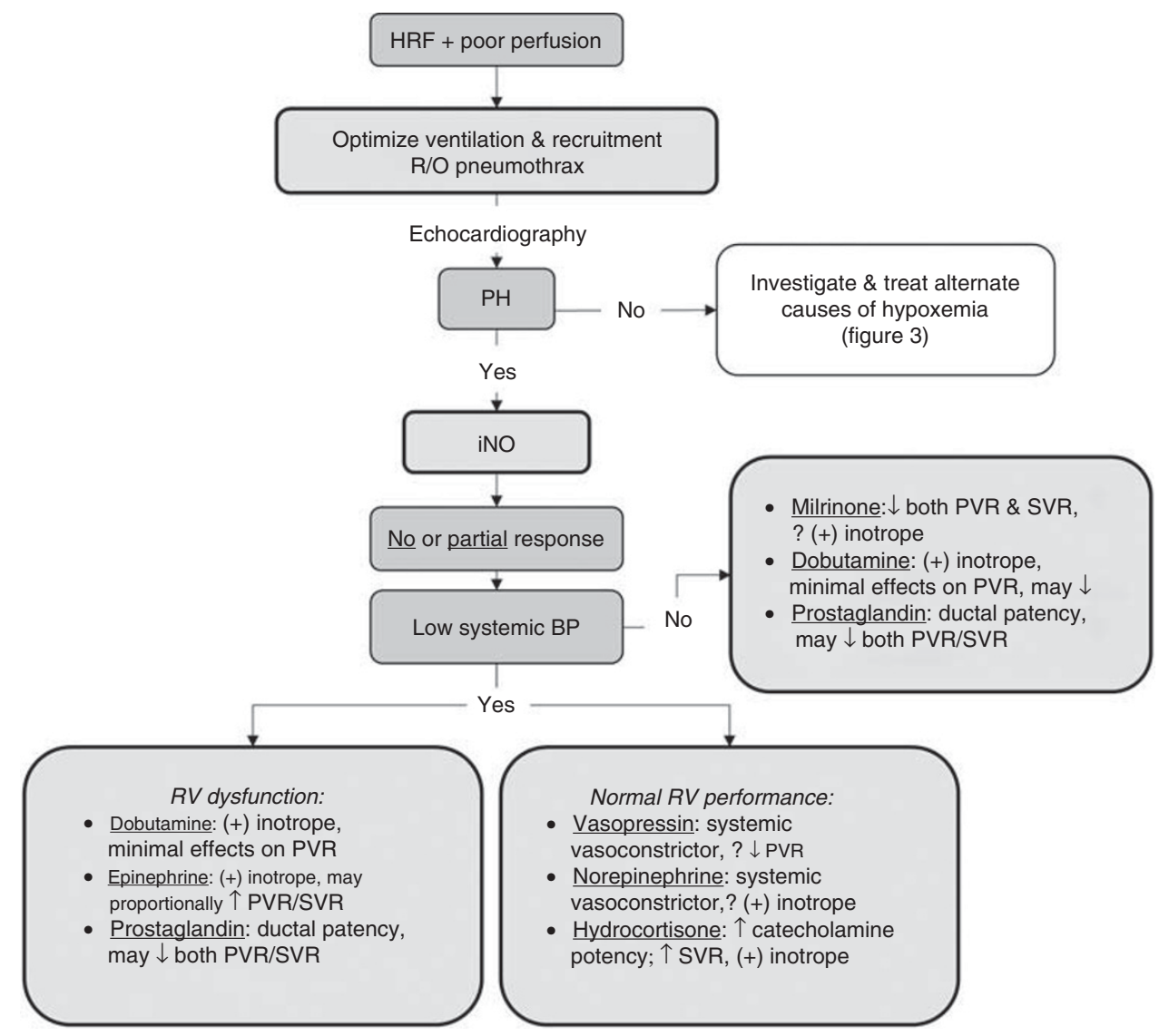

Figure 5. Suggested management algorithm for the preterm infant presenting with HRF. HRF, hypoxemic respiratory failure; iNO, inhaled nitric oxide; PDA, patent ductus arteriosus; PH, pulmonary hypertension; PVR, pulmonary vascular resistance; R/O, rule out; RV, right ventricle; SVR, systemic vascular resistance.

properties may be questionable. Prophylactic milrinone was ineffective at preventing low systemic blood flow in a heterogeneous population of ELBW neonates during the transitional period. These data are difficult to interpret for the following reasons: first, the etiology of low superior vena cava (SVC) flow was not defined, making it difficult to extrapolate to the preterm with acute $\mathrm{PH}$ (106); second, the accuracy of superior vena cava flow as a measurement of systemic blood flow has been questioned in a comparative evaluation with cardiac MRI (107); finally, data from neonatal experimental models also suggest that milrinone may not be efficacious as a positive inotrope in preterms. Milrinone acts, in part, through sarcoplasmic reticulum-dependent modulation of calcium and, therefore, is less efficacious in models where sarcoplasmic reticulum is absent or underdeveloped, such as the immature neonate $(108,109)$. Afterload reduction through PVR may be the primary driver of its proposed efficacy in acute $\mathrm{PH}$. In preterm infants, born at a gestational age between 26 and 31 weeks with echocardiography-confirmed $\mathrm{PH}$, intravenous milrinone has been associated with reduced OI, lower iNO requirement, and improved markers of RV systolic performance (25). Some authors recommend the use of milrinone in neonates with acute $\mathrm{PH}$ and LV dysfunction
(3). This approach may be advantageous if systemic arterial pressure is normal due to the favorable impact of milrinone on RV afterload, RV function, and LV loading conditions (increased preload, reduced afterload). This approach is not without risk, due to the lack of certainty regarding the positive inotropic properties of milrinone in ELBW infants particularly in the transitional period. In addition, milrinone administration to patients with severe LV dysfunction, where the systemic circulation maybe duct-dependent, may cause negative physiologic effects. Specifically, the non-selective vasodilator effects of milrinone lead to a reduction in PVR and increased left heart preload, which may be poorly tolerated resulting in pulmonary edema, and a reduction in cardiac output and SAP (25). Though post-ductal organ perfusion may be augmented by right-to-left ductal shunt in the setting of preserved RV function and elevated PVR, coronary, and cerebral perfusion may be negatively impacted if afterload reduction leads to hypotension and poor perfusion pressure. Moderate dose infusion $(0.5 \mathrm{mcg} / \mathrm{kg} / \mathrm{min})$ has been associated with hypotension in $45 \%$ of patients (106). This is particularly important as the half-life of milrinone may be substantially longer in ELBW (110) as compared with term (111) neonates (10 vs. $4 \mathrm{~h}$, respectively). The evidence 
for other non-selective pulmonary vasodilators (e.g., bosentan (112), prostacyclin analogues (113-115)) in acute $\mathrm{PH}$ is extremely limited and their use as iNO alternatives is not recommended.

\section{Therapy for Hemodynamic Instability}

Treatment of preterm neonates with acute $\mathrm{PH}$ should consider the underlying pathophysiology (Figure 5), as cardiotropic medications may exacerbate HRF if the effects on PVR are not considered. Specific evidence for the use of individual cardiovascular agents in preterm infants with acute $\mathrm{PH}$ is limited, and extrapolation from term and animal data is required. Though commonly used, dopamine and epinephrine have been shown to increase both systemic vascular resistance and PVR (116), and therefore may not be ideal in this population. Dopamine in particular increases PAP to a greater extent than SAP (117) through greater vasoconstriction in the pulmonary vasculature (118). There are no clinical trials of either agent in neonates with acute $\mathrm{PH}$, therefore, these should be used judiciously with careful evaluation of the clinical impact. For neonates with acute $\mathrm{PH}$ and systemic hypotension, alternative cardiovascular agents such as vasopressin and norepinephrine warrant consideration as their biological properties may be more favorable. Vasopressin, a potent systemic vasoconstrictor has been successfully used to treat hypotension in preterm neonates $(119,120)$. In the pulmonary circulation, vasopressin acts through endothelial receptors to increase the release of NO and vasodilates the pulmonary vasculature (121). Data suggesting clinical efficacy are emerging in preterms with acute PH that merits further study (122). Norepinephrine use is also supported by very limited neonatal evidence, however, in animal models it may reduce PVR (123) and support RV function (124), particularly under hypoxic conditions (125). The evidence in term neonates that norepinephrine may improve oxygenation and cardiac output warrants exploration in preterms (126).

For neonates with myocardial dysfunction, dobutamine is an inodilator agent (agonist at cardiac $\alpha 1$ and $\beta 1$ receptors (127)) with positive inotropic properties and has been shown to increase cardiac output in preterm neonates with low SBF (128). In patients with systemic hypotension, however, epinephrine may be advantageous at doses less likely to cause pulmonary vasoconstriction. Though perhaps counterintuitive in the preterm, treatment with prostaglandin $\mathrm{E}_{2}\left(\mathrm{PGE}_{2}\right.$, alprostadil) for refractory hypoxemia or compromised SBF, where RV systolic performance is severely impaired and the PDA is small or restrictive, may be advantageous. In this setting, right-to-left ductal shunt may augment post-ductal cardiac output and improve organ perfusion (129) Though the $\mathrm{PaO}_{2}$ is lower, it may be sufficient to prevent anaerobic metabolism and organ ischemia. The beneficial effects for the $\mathrm{RV}$ include afterload reduction due to run-off into the systemic circulation and the vasodilator properties of $\mathrm{PGE}_{2}$ may reduce PVR (130).
TnECHO assessment is recommended in the management of all preterm infants with suspected $\mathrm{PH}$ and cardiovascular instability. The ability to provide non-invasive longitudinal data may allow for greater therapeutic precision, in particular more comprehensive evaluation of the merits or unintended consequences of cardiovascular support. Newer techniques such as tissue Doppler imaging and myocardial strain measurement may provide novel insights regarding the impact of elevated PVR on RV function and their relationship to neonatal outcomes; however, these techniques require prospective validation.

\section{CONCLUSION}

Though increasingly recognized as an important contributor to hypoxia and acute cardiovascular instability, the optimum care for premature neonates with acute $\mathrm{PH}$ remains poorly understood and controversial. It is a complex and heterogeneous disease that requires a high index of suspicion to identify and meticulous attention to detail to optimize management. Enhanced understanding of physiology may aid in the interpretation of conflicting literature and should inform clinical practice. Appropriate patient selection is of paramount importance, as there is likely a population of preterm neonates who benefit from iNO as an acute rescue therapy after alveolar aeration and recruitment strategies are optimized. Comprehensive TnECHO evaluation may provide an enhanced understanding of mechanism of disease, facilitate earlier identification of a target population where early intervention may be beneficial, and exclude confounding illnesses (e.g., CHD, LV dysfunction) where non-judicious use of iNO or alternative pulmonary vasodilators may be harmful. A thoughtful, physiological, and targeted approach to therapy may improve patient outcomes and provide direction for future clinical trials.

Disclosure: The authors declare no conflict of interest.

\section{REFERENCES}

1. Finer NN, Barrington KJ. Nitric oxide for respiratory failure in infants born at or near term. Cochrane Database Syst Rev 2001: Cd000399.

2. Barrington KJ, Finer N, Pennaforte T. Inhaled nitric oxide for respiratory failure in preterm infants. Cochrane Database Syst Rev 2017: 1Cd000509.

3. Abman SH, Hansmann G, Archer SL, et al. Pediatric pulmonary hypertension: guidelines from the American Heart Association and American Thoracic Society. Circulation 2015;132:2037-99.

4. Pejovic B, Peco-Antic A, Marinkovic-Eric J. Blood pressure in noncritically ill preterm and full-term neonates. Pediatr Nephrol 2007;22: 249-57.

5. Rudolph AM, Auld PA, Golinko RJ, Paul MH. Pulmonary vascular adjustments in the neonatal period. Pediatrics 1961;28:28-34.

6. Popat H, Kluckow M. Noninvasive assessment of the early transitional circulation in healthy term infants. Neonatology 2012;101:166-71.

7. Kumar VH, Hutchison AA, Lakshminrusimha S, Morin FC 3rd, Wynn RJ, Ryan RM. Characteristics of pulmonary hypertension in preterm neonates. J Perinatol 2007;27:214-9.

8. Jain A, McNamara P. Persistent pulmonary hypertension of the newborn: physiology, hemodynamic assessment and novel therapies. Semin Fetal Neonatal Med 2015;20:262-71. 
9. Brannon TS, North AJ, Wells LB, Shaul PW. Prostacyclin synthesis in ovine pulmonary artery is developmentally regulated by changes in cyclooxygenase-1 gene expression. J Clin Investig 1994;93:2230-5.

10. Dhillon R. The management of neonatal pulmonary hypertension. Arch Dis Child Fetal Neonatal Ed 2012;97:F223-8.

11. Musewe NN, Poppe D, Smallhorn JF, et al. Doppler echocardiographic measurement of pulmonary artery pressure from ductal Doppler velocities in the newborn. J Am Coll Cardiol 1990;15:446-56.

12. James AT, Corcoran JD, Jain A, et al. Assessment of myocardial performance in preterm infants less than 29 weeks gestation during the transitional period. Early Hum Dev 2014;90:829-35.

13. Slama M, Susic D, Varagic J, Ahn J, Frohlich ED. Echocardiographic measurement of cardiac output in rats. Am J Physiol Heart Circ Physiol 2003;284:H691-7.

14. Szymankiewicz M, Matuszczak-Wleklak M, Vidyasagar D, Gadzinowski J. Retrospective diagnosis of hypoxic myocardial injury in premature newborns. J Perinat Med 2006;34:220-5.

15. Simpson LL, Marx GR, Elkadry EA, D'Alton ME. Cardiac dysfunction in twin-twin transfusion syndrome: a prospective, longitudinal study. Obstet Gynecol 1998;92 (4 Pt 1): 557-62.

16. Toyono M, Harada K, Takahashi Y, Takada G. Maturational changes in left ventricular contractile state. Int J Cardiol 1998;64:247-52.

17. Igarashi $H$, Shiraishi $H$, Endoh $H$, Yanagisawa $M$. Left ventricular contractile state in preterm infants: relation between wall stress and velocity of circumferential fiber shortening. Am Heart J 1994;127:1336-40.

18. Simonneau G, Gatzoulis MA, Adatia I, et al. Updated clinical classification of pulmonary hypertension. J Am Coll Cardiol 2013;62 (25 Suppl): D34-41.

19. Friedman WF. The intrinsic physiologic properties of the developing heart. Prog Cardiovasc Dis 1972;15:87-111.

20. Rudolph AM. Myocardial growth before and after birth: clinical implications. Acta Paediatr 2000;89:129-33.

21. Page E, Buecker JL. Development of dyadic junctional complexes between sarcoplasmic reticulum and plasmalemma in rabbit left ventricular myocardial cells. Morphometric analysis. Circ Res 1981;48: $519-22$.

22. Reed KL, Sahn DJ, Scagnelli S, Anderson CF, Shenker L. Doppler echocardiographic studies of diastolic function in the human fetal heart: changes during gestation. J Am Coll Cardiol 1986;8:391-5.

23. Romero TE, Friedman WF. Limited left ventricular response to volume overload in the neonatal period: a comparative study with the adult animal. Pediatr Res 1979;13:910-5.

24. Vachiery JL, Adir Y, Barbera JA, et al. Pulmonary hypertension due to left heart diseases. J Am Coll Cardiol 2013;62 (25 Suppl): D100-8.

25. James AT, Bee C, Corcoran JD, McNamara PJ, Franklin O, El-Khuffash AF. Treatment of premature infants with pulmonary hypertension and right ventricular dysfunction with milrinone: a case series. J Perinatol 2015;35:268-73.

26. Malowitz JR, Forsha DE, Smith PB, Cotten CM, Barker PC, Tatum GH. Right ventricular echocardiographic indices predict poor outcomes in infants with persistent pulmonary hypertension of the newborn. Eur Heart J Cardiovasc Imaging 2015;16:1224-31.

27. Maskatia SA, Pignatelli RH, Ayres NA, Altman CA, Sangi-Haghpeykar H, Lee W. Longitudinal changes and interobserver variability of systolic myocardial deformation values in a prospective cohort of healthy fetuses across gestation and after delivery. J Am Soc Echocardiogr 2016;29:341-9.

28. Younoszai AK, Saudek DE, Emery SP, Thomas JD. Evaluation of myocardial mechanics in the fetus by velocity vector imaging. J Am Soc Echocardiogr 2008;21:470-4.

29. Rudolph AM, Heymann MA. Circulatory changes during growth in the fetal lamb. Circ Res 1970;26:289-99.

30. Reller MD, Morton MJ, Giraud GD, Wu DE, Thornburg KL. Severe right ventricular pressure loading in fetal sheep augments global myocardial blood flow to submaximal levels. Circulation 1992;86: $581-8$.
31. Jonker SS, Louey S, Giraud GD, Thornburg KL, Faber JJ. Timing of cardiomyocyte growth, maturation, and attrition in perinatal sheep. FASEB J 2015;29:4346-57.

32. Thornburg KL, Morton MJ. Filling and arterial pressures as determinants of RV stroke volume in the sheep fetus. Am J Physiol 1983;244:H656-63.

33. Johnson RC, Datar SA, Oishi PE, et al. Adaptive right ventricular performance in response to acutely increased afterload in a lamb model of congenital heart disease: evidence for enhanced Anrep effect. Am J Physiol Heart Circ Physiol 2014;306:H1222-30.

34. St John Sutton MG, Meyer RA. Left ventricular function in persistent pulmonary hypertension of the newborn. Computer analysis of the echocardiogram. Br Heart J 1983;50:540-9.

35. Poveda F, Gil D, Marti E, Andaluz A, Ballester M, Carreras F. Helical structure of the cardiac ventricular anatomy assessed by diffusion tensor magnetic resonance imaging with multiresolution tractography. Rev Esp Cardiol (Engl Ed) 2013;66:782-90.

36. Milstein JM, Glantz SA. Mechanically increased right ventricular afterload alters left ventricular configuration, not contractility, in neonatal lambs. Pediatr Res 1993;33 (4 Pt 1): 359-64.

37. Weil SR, Russo PA, Heckman JL, Balsara RK, Pasiecki V, Dunn JM. Pressure-volume relationship of the fetal lamb heart. Ann Thorac Surg 1993;55:470-5.

38. Gan C, Lankhaar JW, Marcus JT, et al. Impaired left ventricular filling due to right-to-left ventricular interaction in patients with pulmonary arterial hypertension. Am J Physiol Heart Circ Physiol 2006;290: H1528-33.

39. Hauge A.. Hypoxia and pulmonary vascular resistance. The relative effects of pulmonary arterial and alveolar PO2. Acta Physiol Scand 1969;76:121-30.

40. Rudolph AM, Yuan S. Response of the pulmonary vasculature to hypoxia and $\mathrm{H}+$ ion concentration changes. J Clin Investig 1966;45: 399-411.

41. Lewis AB, Heymann MA, Rudolph AM. Gestational changes in pulmonary vascular responses in fetal lambs in utero. Circulation Res 1976;39:536-41.

42. Morin FC 3rd, Egan EA. Pulmonary hemodynamics in fetal lambs during development at normal and increased oxygen tension. J Appl Physiol 1992;73:213-8.

43. Patel A, Lakshminrusimha S, Ryan RM, et al. Exposure to supplemental oxygen downregulates antioxidant enzymes and increases pulmonary arterial contractility in premature lambs. Neonatology 2009;96: 182-92.

44. Walther FJ, Wade AB, Warburton D, Forman HJ. Ontogeny of antioxidant enzymes in the fetal lamb lung. Exp Lung Res 1991;17:39-45.

45. Frank L, Sosenko IR. Prenatal development of lung antioxidant enzymes in four species. J Pediatr 1987;110:106-10.

46. Autor AP, Frank L, Roberts RJ. Developmental characteristics of pulmonary superoxide dismutase: relationship to idiopathic respiratory distress syndrome. Pediatr Res 1976;10:154-8.

47. Frank L, Lewis PL, Sosenko IR. Dexamethasone stimulation of fetal rat lung antioxidant enzyme activity in parallel with surfactant stimulation. Pediatrics 1985;75:569-74.

48. Frank L, Sosenko IR. Failure of premature rabbits to increase antioxidant enzymes during hyperoxic exposure: increased susceptibility to pulmonary oxygen toxicity compared with term rabbits. Pediatr Res 1991;29:292-6.

49. Kelly FJ, Rickett GW, Phillips GJ. Magnitude of hyperoxic stress and degree of lung maturity determine the nature of pulmonary antioxidant response in the guinea pig. Free Radical Res Commun 1992;17: $335-47$.

50. Morton RL, Das KC, Guo XL, Ikle DN, White CW. Effect of oxygen on lung superoxide dismutase activities in premature baboons with bronchopulmonary dysplasia. Am J Physiol 1999;276 (1 Pt 1): L64-74.

51. Belik J, Jankov RP, Pan J, Tanswell AK. Peroxynitrite inhibits relaxation and induces pulmonary artery muscle contraction in the newborn rat. Free Radical Biol Med 2004;37:1384-92. 
52. Walsh BK. Oxygen Administration. Neonatal and Pediatric Respiratory Care. St. Louis, MO, USA: Elsevier Health Sciences, 2014 pp 148-62.

53. Carlo WA, Finer NN, Walsh MC, et al. Target ranges of oxygen saturation in extremely preterm infants. New Engl J Med 2010;362:1959-69.

54. Stenson BJ, Tarnow-Mordi WO, Darlow BA, et al. Oxygen saturation and outcomes in preterm infants. New Engl J Med 2013;368:2094-104.

55. Creamer KM, McCloud LL, Fisher LE, Ehrhart IC. Ventilation above closing volume reduces pulmonary vascular resistance hysteresis. Am J Respir Crit Care Med 1998;158:1114-9.

56. Dimitriou G, Greenough A, Kavadia V. Early measurement of lung volume-a useful discriminator of neonatal respiratory failure severity. Physiol Meas 1996;17:37-42.

57. Dinger J, Topfer A, Schaller P, Schwarze R. Functional residual capacity and compliance of the respiratory system after surfactant treatment in premature infants with severe respiratory distress syndrome. Eur J Pediatr 2002;161:485-90.

58. Tarawneh A, Kaczmarek J, Bottino MN, Sant'anna GM. Severe airway obstruction during surfactant administration using a standardized protocol: a prospective, observational study. J Perinatol 2012;32:270-5.

59. Whittenberger JL, Mc GM, Berglund E, Borst HG. Influence of state of inflation of the lung on pulmonary vascular resistance. J Appl Physiol 1960;15:878-82.

60. Polglase GR, Morley CJ, Crossley KJ, et al. Positive end-expiratory pressure differentially alters pulmonary hemodynamics and oxygenation in ventilated, very premature lambs. J Appl Physiol 2005;99:1453-61.

61. Reller MD, Donovan EF, Kotagal UR. Influence of airway pressure waveform on cardiac output during positive pressure ventilation of healthy newborn dogs. Pediatr Res 1985;19:337-41.

62. Tana M, Polglase GR, Cota F, et al. Determination of lung volume and hemodynamic changes during high-frequency ventilation recruitment in preterm neonates with respiratory distress syndrome. Crit Care Med 2015;43:1685-91.

63. Thome U, Topfer A, Schaller P, Pohlandt F. Effects of mean airway pressure on lung volume during high-frequency oscillatory ventilation of preterm infants. Am J Respir Crit Care Med 1998;157 (4 Pt 1): 1213-8.

64. Thome U, Topfer A, Schaller P, Pohlandt F. Comparison of lung volume measurements by antero-posterior chest X-ray and the SF6 washout technique in mechanically ventilated infants. Pediatr Pulmonol 1998;26: 265-72.

65. Suzuki H, Papazoglou K, Bryan AC. Relationship between $\mathrm{PaO} 2$ and lung volume during high frequency oscillatory ventilation. Acta Paediatr Jpn 1992;34:494-500.

66. Tana M, Zecca E, Tirone $\mathrm{C}$, et al. Target fraction of inspired oxygen during open lung strategy in neonatal high frequency oscillatory ventilation: a retrospective study. Minerva Anestesiol 2012;78:151-9.

67. De Jaegere A, van Veenendaal MB, Michiels A, van Kaam AH. Lung recruitment using oxygenation during open lung high-frequency ventilation in preterm infants. Am J Respir Crit Care Med 2006;174:639-45.

68. Zannin E, Doni D, Ventura ML, et al. Relationship between mean airways pressure, lung mechanics, and right ventricular output during highfrequency oscillatory ventilation in infants. J Pediatr 2017;180:110-5.

69. de Waal K, Evans N, van der Lee J, van Kaam A. Effect of lung recruitment on pulmonary, systemic, and ductal blood flow in preterm infants. J Pediatr 2009;154:651-5.

70. Liu YA, Theis JG, Coceani F. Contractile and relaxing mechanisms in pulmonary resistance arteries of the preterm fetal lamb. Biol Neonate 2000;77:253-60.

71. Skimming JW, DeMarco VG, Cassin S. The effects of nitric oxide inhalation on the pulmonary circulation of preterm lambs. Pediatr Res 1995;37:35-40.

72. Kinsella JP, Walsh WF, Bose CL, et al. Inhaled nitric oxide in premature neonates with severe hypoxaemic respiratory failure: a randomised controlled trial. Lancet 1999;354:1061-5.

73. Van Meurs KP, Wright LL, Ehrenkranz RA, et al. Inhaled nitric oxide for premature infants with severe respiratory failure. New Engl J Med 2005;353:13-22.
74. Su PH, Chen JY. Inhaled nitric oxide in the management of preterm infants with severe respiratory failure. J Perinatol 2008;28:112-6.

75. Wei QF, Pan XN, Li Y, et al. [Efficacy of inhaled nitric oxide in premature infants with hypoxic respiratory failure]. Zhongguo Dang Dai Er Ke Za Zhi=Chin J Contemp Pediatr 2014;16:805-9.

76. Dani C, Bertini G, Pezzati M, Filippi L, Cecchi A, Rubaltelli FF. Inhaled nitric oxide in very preterm infants with severe respiratory distress syndrome. Acta Paediatr 2006;95:1116-23.

77. The Franco-Belgium Collaborative NO Trial Group. Early compared with delayed inhaled nitric oxide in moderately hypoxaemic neonates with respiratory failure: a randomised controlled trial. The FrancoBelgium Collaborative NO Trial Group. Lancet 1999;354:1066-71.

78. Abman SH, Kinsella JP, Schaffer MS, Wilkening RB. Inhaled nitric oxide in the management of a premature newborn with severe respiratory distress and pulmonary hypertension. Pediatrics 1993;92:606-9.

79. Uga N, Ishii T, Kawase Y, Arai H, Tada H. Nitric oxide inhalation therapy in very low-birthweight infants with hypoplastic lung due to oligohydramnios. Pediatr Int 2004;46:10-4.

80. Chock VY, Van Meurs KP, Hintz SR, et al. Inhaled nitric oxide for preterm premature rupture of membranes, oligohydramnios, and pulmonary hypoplasia. Am J Perinatol 2009;26:317-22.

81. Semberova J, O'Donnell SM, Franta J, Miletin J. Inhaled nitric oxide in preterm infants with prolonged preterm rupture of the membranes: a case series. J Perinatol 2015;35:304-6.

82. Mohamed AS, Mohamed I, Baczynski M, et al. Echocardiography predictors of response to inhaled nitric oxide therapy in hypoxic preterm neonates. Pediatric Academic Society Meeting 2017. ePAS 2702862; San Francisco, USA.

83. Su BH, Lin HY, Huang FK, Tsai ML, Huang YT. Circulatory management focusing on preventing intraventricular hemorrhage and pulmonary hemorrhage in preterm infants. Pediatr Neonatol 2016;57:453-62.

84. Noori S, Seri I. Hemodynamic antecedents of peri/intraventricular hemorrhage in very preterm neonates. Semin Fetal Neonatal Med 2015;20:232-7.

85. Desandes R, Desandes E, Droulle P, Didier F, Longrois D, Hascoet JM. Inhaled nitric oxide improves oxygenation in very premature infants with low pulmonary blood flow. Acta Paediatr 2004;93:66-9.

86. Berkelhamer SK, Farrow KN. Developmental regulation of antioxidant enzymes and their impact on neonatal lung disease. Antioxid Redox Signal 2014;21:1837-48.

87. Barrington KJ, Finer N. Inhaled nitric oxide for respiratory failure in preterm infants. Cochrane Database Syst Rev 2010: Cd000509.

88. Watson RS, Clermont G, Kinsella JP, et al. Clinical and economic effects of iNO in premature newborns with respiratory failure at 1 year. Pediatrics 2009;124:1333-43.

89. Chandrasekharan P, Kozielski R, Kumar VH, et al. Early use of inhaled nitric oxide in preterm infants: is there a rationale for selective approach? Am J Perinatol 2016;34:428-40.

90. Baczynski M, Ginty S, Weisz DE, et al. Short-term and long-term outcomes of preterm neonates with acute severe pulmonary hypertension following rescue treatment with inhaled nitric oxide. Arch Dis Child Fetal Neonatal Ed 2017;0:F1-F7.

91. Rodriguez-Castano MJ, Aleo E, Arruza L. Oral sildenafil for severe pulmonary hypertension developing after ibuprofen use in a neonate. Indian Pediatr 2016;53:349-50.

92. Steiner M, Salzer U, Baumgartner S, et al. Intravenous sildenafil i.v. as rescue treatment for refractory pulmonary hypertension in extremely preterm infants. Klin Padiatr 2014;226:211-5.

93. Marsh CS, Marden B, Newsom R. Severe retinopathy of prematurity (ROP) in a premature baby treated with sildenafil acetate (Viagra) for pulmonary hypertension. Br J Ophthalmol 2004;88:306-7.

94. Jayadev C, Ramasastry P, Gul A, Vinekar A. Possible role of sildenafil citrate in the recurrence of neovascularization in laser-regressed aggressive posterior ROP. Indian Pediatr 2016;53 (Suppl 2): S155-6.

95. Fuwa K, Hosono S, Nagano N, Takahashi S, Nakashima M. Retinopathy of prematurity after sildenafil treatment. Pediatr Int 2017;59:360-1. 
96. Fang AY, Guy KJ, Konig K. The effect of sildenafil on retinopathy of prematurity in very preterm infants. J Perinatol 2013;33:218-21.

97. Samiee-Zafarghandy S, van den Anker JN, Laughon MM, Clark RH, Smith PB, Hornik CP. Sildenafil and retinopathy of prematurity risk in very low birth weight infants. J Perinatol 2016;36:137-40.

98. Fawzi AA, Chou JC, Kim GA, Rollins SD, Taylor JM, Farrow KN. Sildenafil attenuates vaso-obliteration and neovascularization in a mouse model of retinopathy of prematurity. Invest Ophthalmol Vis Sci 2014;55:1493-501.

99. Balasubramanian H, Strunk T, Kohan R. Arterial hypotension and prerenal failure in an extremely preterm infant associated with oral sildenafil. J Perinatol 2015;35:458-9.

100. Mukherjee A, Dombi T, Wittke B, Lalonde R. Population pharmacokinetics of sildenafil in term neonates: evidence of rapid maturation of metabolic clearance in the early postnatal period. Clin Pharmacol Ther 2009;85:56-63.

101. Hines RN. Ontogeny of human hepatic cytochromes P450. J Biochem Mol Toxicol 2007;21:169-75.

102. Bhatt-Mehta V, Donn SM. Sildenafil for pulmonary hypertension complicating bronchopulmonary dysplasia. Expert Rev Clin Pharmacol 2014;7:393-5.

103. Rao S, Bartle D, Patole S. Current and future therapeutic options for persistent pulmonary hypertension in the newborn. Expert Rev Cardiovasc Ther 2010;8:845-62.

104. Timmis AD, Smyth P, Monaghan M, et al. Milrinone in heart failure. Acute effects on left ventricular systolic function and myocardial metabolism. Br Heart J 1985;54:36-41.

105. Deb B, Bradford K, Pearl RG. Additive effects of inhaled nitric oxide and intravenous milrinone in experimental pulmonary hypertension. Crit Care Med 2000;28:795-9.

106. Paradisis M, Evans N, Kluckow M, Osborn D, McLachlan AJ. Pilot study of milrinone for low systemic blood flow in very preterm infants. J Pediatr 2006;148:306-13.

107. Ficial B, Finnemore AE, Cox DJ, et al. Validation study of the accuracy of echocardiographic measurements of systemic blood flow volume in newborn infants. J Am Soc Echocardiogr 2013;26:1365-71.

108. Sys SU, Goenen MJ, Chalant CH, Brutsaert DL. Inotropic effects of amrinone and milrinone on contraction and relaxation of isolated cardiac muscle. Circulation 1986;73 (3 Pt 2): Iii25-35.

109. Ogawa S, Nakanishi T, Kamata K, Takao A. Effect of milrinone on myocardial mechanical function and cyclic AMP content in the fetal rabbit. Pediatr Res 1987;22:282-5.

110. Paradisis M, Jiang X, McLachlan AJ, Evans N, Kluckow M, Osborn D. Population pharmacokinetics and dosing regimen design of milrinone in preterm infants. Arch Dis Child Fetal Neonatal Ed 2007;92:F204-9.

111. McNamara PJ, Shivananda SP, Sahni M, Freeman D, Taddio A. Pharmacology of milrinone in neonates with persistent pulmonary hypertension of the newborn and suboptimal response to inhaled nitric oxide. Pediatr Crit Care Med 2013;14:74-84.

112. Gurakan B, Kayiran P, Ozturk N, Kayiran SM, Dindar A. Therapeutic combination of sildenafil and iloprost in a preterm neonate with pulmonary hypertension. Pediatr Pulmonol 2011;46:617-20.

113. Yilmaz O, Kahveci H, Zeybek C, Ciftel M, Kilic O. Inhaled iloprost in preterm infants with severe respiratory distress syndrome and pulmonary hypertension. Am J Perinatol 2014;31:321-6.

114. De Jaegere AP, van den Anker JN. Endotracheal instillation of prostacyclin in preterm infants with persistent pulmonary hypertension. Eur Respir J 1998;12:932-4.

115. Soditt V, Aring C, Groneck P. Improvement of oxygenation induced by aerosolized prostacyclin in a preterm infant with persistent pulmonary hypertension of the newborn. Intensive Care Med 1997;23:1275-8.

116. Barrington KJ, Finer NN, Chan WK. A blind, randomized comparison of the circulatory effects of dopamine and epinephrine infusions in the newborn piglet during normoxia and hypoxia. Crit Care Med 1995;23:740-8.
117. Cheung PY, Barrington KJ, Pearson RJ, Bigam DL, Finer NN, Van Aerde JE. Systemic, pulmonary and mesenteric perfusion and oxygenation effects of dopamine and epinephrine. Am J Respir Crit Care Med 1997;155:32-7.

118. Moraes-Silva MA, Andrade RR, Oliveira RA, Spadaro J, Curi PR, Hossne WS. Effects of dopamine on the pulmonary circulation of the dog. Braz J Med Biol Res 1984;17:75-82.

119. Ikegami H, Funato M, Tamai H, Wada H, Nabetani M, Nishihara M. Low-dose vasopressin infusion therapy for refractory hypotension in ELBW infants. Pediatr Int 2010;52:368-73.

120. Rios DR, Kaiser JR. Vasopressin versus dopamine for treatment of hypotension in extremely low birth weight infants: a randomized, blinded pilot study. J Pediatr 2015;166:850-5.

121. Holmes CL, Patel BM, Russell JA, Walley KR. Physiology of vasopressin relevant to management of septic shock. Chest 2001;120:989-1002.

122. Mohamed A, Louis D, Surak A, Weisz DE, McNamara PJ, Jain A. Outcomes of Preterm Neonates Treated with Vasopressin for Refractory Pulmonary Hypertension: Case Series. Baltimore, MD, USA: Pediatric Academic Society, 2016.

123. Tulloh RM, Dyamenahalli U, Stuart-Smith K, Haworth SG. Adrenoceptor-stimulated endothelium-dependent relaxation in porcine intrapulmonary arteries. Pulm Pharmacol 1994;7:299-303.

124. Hirsch LJ, Rooney MW, Wat SS, Kleinmann B, Mathru M. Norepinephrine and phenylephrine effects on right ventricular function in experimental canine pulmonary embolism. Chest 1991;100:796-801.

125. Cutaia M, Friedrich P. Hypoxia-induced alterations of norepinephrine vascular reactivity in isolated perfused cat lung. J Appl Physiol 1987;63:982-7.

126. Tourneux P, Rakza T, Bouissou A, Krim G, Storme L. Pulmonary circulatory effects of norepinephrine in newborn infants with persistent pulmonary hypertension. J Pediatr 2008;153:345-9.

127. Ruffolo RR Jr. The pharmacology of dobutamine. Am J Med Sci 1987;294:244-8.

128. Osborn D, Evans N, Kluckow M. Randomized trial of dobutamine versus dopamine in preterm infants with low systemic blood flow. J Pediatr 2002;140:183-91.

129. Graham EM, Bradley SM, Atz AM. Preoperative management of hypoplastic left heart syndrome. Expert Opin Pharmacother 2005;6:687-93.

130. Cassin S, Tyler T, Leffler C, Wallis R. Pulmonary and systemic vascular responses of perinatal goats to prostaglandins E1 and E2. Am J Physiol 1979;236:H828-32.

131. Fisher EA, Goldman ME. Simple, rapid method for quantification of tricuspid regurgitation by two-dimensional echocardiography. Am J Cardiol 1989;63:1375-8.

132. Ryan T, Petrovic O, Dillon JC, Feigenbaum H, Conley MJ, Armstrong WF. An echocardiographic index for separation of right ventricular volume and pressure overload. J Am Coll Cardiol 1985;5:918-27.

133. Kitabatake $A$, Inoue $M$, Asao $M$, et al. Noninvasive evaluation of pulmonary hypertension by a pulsed Doppler technique. Circulation 1983;68:302-9.

134. Badano LP, Ginghina C, Easaw J, et al. Right ventricle in pulmonary arterial hypertension: haemodynamics, structural changes, imaging, and proposal of a study protocol aimed to assess remodelling and treatment effects. Eur J Echocardiogr 2010;11:27-37.

135. Jain A, Mohamed A, El-Khuffash A, et al. A comprehensive echocardiographic protocol for assessing neonatal right ventricular dimensions and function in the transitional period: normative data and z scores. J Am Soc Echocardiogr 2014;27:1293-304.

136. Aloia E, Cameli M, D'Ascenzi F, Sciaccaluga C, Mondillo S. TAPSE: an old but useful tool in different diseases. Int J Cardiol 2016;225:177-83.

137. Srisuparp P, Heitschmidt M, Schreiber MD. Inhaled nitric oxide therapy in premature infants with mild to moderate respiratory distress syndrome. J Med Assoc Thai 2002;85 (Suppl 2): S469-78. 